one or more rain-makers in a local group who either confine their magical activities to this sphere or are fully initiated medicine-men. In most tribes women cannot witness the rites; in others they participate in some methods or perform a simple type of magical act themselves.

The methods employed by the rain-makers are surprisingly varied, originating as they do in a dream, as a traditional rite performed by the dream-people, or from an incident in daily life which has been followed by rain. Many of the methods are imitative of clouds and falling rain, and of aquatic animals; others seek to persuade the ancestral beings to release the rain, and some medicine-men believe they can go up to the sky to open the clouds.

The Dieri and other tribes of the Lake Eyre district believe that the mura-mura, their spiritual ancestors who made and inhabited the earth in the dream-time prior to man's occupation, now live in the sky, and some of them have to be influenced by ceremonies to release the rain from the clouds.

In south-east Australia storms of wind and rain, and also floods, were believed to be sent by enemies to disturb hunting and fishing activities. The Kurnai of Gippsland squirted water from the mouth in the direction from which rain usually came, and sang magical rain chants acquired in dreams by both men and women.

In Arnhem Land pounded bark (used for poisoning fish) is wrapped in grass, weighted in stones, and taken out into either salt or fresh water by a man until his shoulders are covered; here he drops the bundle, sings a song about falling rain, and pushes the water with his hands to represent the rain splashing on its surface. He expects the clouds to form in about three days and the rain to come on the fourth day after this rite. Here, too, a large bundle of green grass fashioned into a human image is buried and when it swells up rain is expected to fall. The rain is stopped by taking the grass out of the water or ground and spreading it out to dry.

\section{AIR MASS CLIMATOLOGY OF THE BRITISH ISLES}

COME simple facts about the air mass climatology $S$ of the British Isles, such as the difference between the relative coldness of east and the relative warmth of south-west winds in winter, have been common knowledge for ages. In the second and third decades of this century the Norwegian school of meteorologists, led by V. and J. Bjerknes, elaborated the ideas of Shaw, Lempfert and others to depict the atmosphere as 'organized' not only into cyclonic and anticyclonic systems but also into warm and cold air masses (often referred to respectively as tropical and polar air) with different life-histories. The interplay of different air masses was shown to produce the day-to-day weather changes of the temperate and polar regions.

In a recent Air Ministry/Meteorological Office* memoir, which is a contribution to synoptic climatology, Dr. J. E. Belasco has investigated the more important physical properties of the atmosphere over the British Isles in twenty-one subdivisions of

* Air Ministry : Meteorological Office. Geophysical Memoir No. By Dr. J. E. Belasco. Pp. 34. (London: H.M.S.O., 1952.) 2s. 6d. net. tropical and polar air, using surface and upper-air data for the period 1931-45. The generalized tracks over which the air masses reach the British Isles are shown by maps, and the frequency of occurrence of the air masses and the average temperature and humidity of the atmosphere in them at the surface at Kew Observatory and in the upper air up to 450 mb. (about $6 \mathrm{~km}$.) over the British Isles are set out in tables and thermodynamic diagrams. There is also a discussion of the changes of temperature and humidity which maritime tropical and direct polar air masses undergo as, on their way to the British Isles, they pass over a surface respectively colder and warmer than their lowest layers. With the aid of this memoir, it has now become possible for the first time to explain some aspects of the climate of the British Isles in terms of the incidence and of the physical properties of different air masses instead of describing them statistically by the usual presentation of means and extremes.

The discussion shows that the correspondence between air mass and wind direction is quite rough and far from unique. Thus, north-west winds usually bring a cold air mass with a large fall of temperature with height and rssociated showery weather; but when an anticyclone remains stationary westward of Ireland, such winds can bring air originating over the sub-tropical Atlantic which has been cooled from below on its way. Again, polar air of a particularly unstable type can come with a south wind having travelled around a stationary depression centred south-west of Ireland. Quite the coldest air mass is, as is well known, the one which comes in winter from Russia and reaches the British Isles from the east or south-east. This air mass has in January a mean maximum temperature of $31^{\circ} \mathrm{F}$. at Kew. The warmest air mass in January comes from the Madeira area and has a mean maximum of $53^{\circ} \mathrm{F}$. at Kew. In July the temperature differences between the coldest and warmest air masses are nearly as great as in January. Air of west Mediterranean origin has at Kew in July a mean maximum of $82^{\circ} \mathrm{F}$. and air direct from the sea north of Norway a mean maximum of $64^{\circ}$. The differences of temperature between air masses in the upper air are larger than at the surface because the primary heating and cooling occur at the surface.

Dr. Belasco's memoir will be of value not only to those seeking a physical explanation of British climate, but also to the weather forecaster in stating the weather to be expected in an air mass the arrival of which he has foretold.

\section{PAPER PULP RESEARCH AT THE DEHRA DUN RESEARCH INSTITUTE}

TNVESTIGATIONS on the pulping of illuk grass (Imperata arundinacea) by the soda and the mono-sulphite processes* have been undertaken at the Forest Research Institute, Dehra Dun, at the request of the Ceylon Government, which forwarded samples for the purpose, with the view of ascertaining the respective economics and suitability of the two

* Indian Forest Bulletin No. 145: Pulping of Illuk Grass (Imperata arundinacea) by Soda and Mono-Sulphite Processes. By Chattar lications, 1951.) Anuas $8 ; 9 d$. 
processes to the species. Kesearch has shown that the cost of chemicals required for pulping the grass by the mono-sulphite process is 38 per cent more than that required by the soda process. Of the two methods of digestion, namely, 'overhead' and 'fractional', as applicable to the soda process, the 'fractional' method of digestion appears to be more suitable, as well as more economical, for pulping of illuk grass.

In Indian Forest Leaflet No. 124 of the Research Institute*, R. V. Bhat and N. S. Jaspal discuss investigations on pulps for writing and printing papers from the castor oil plant (Ricinus communis). In India, so far, bamboo and sabai grass (Eulaliopsis binata) are the chief raw materials used in the paper industry. The local supplies of these materials are insufficient to meet the requirements of the existing mills. Bamboos are used in India for a large variety of other purposes, and the sabai grass only grows in particular areas. The production of paper in Indian mills in 1949 amounted to 170,000 tons. To meet domestic demands for paper, a large quantity is annually imported, and these demands are increasing. The instalment of further new pulp plants depends upon larger amounts of raw material being available.

Reimold had advocated the cultivation of the castor oil plant in America, as a high-grade cellulose could be produced at a low price owing to the cheapness of the raw material. The castor oil plant is commonly grown as an annual crop in several parts of India for its seeds, from which the oil is obtained, and it is upon the stalks, for the purpose of making pulp, that experiments were made at Dehra Dun. The plant is also grown as a perennial small tree, and this, too, was the subject of research work.

The conclusions arrived at are as follows. Easybleaching pulps with satisfactory strength properties can be prepared from stems of castor oil plants by the soda and the sulphite processes, the latter being the more suitable. 'The stems of the annual and the perennial varieties can be used for pulping without the removal of the bark. The pulps from the wood are short-fibred, whereas those from the bark are long-fibred. Owing to this, pilot-plant experiments will have to be carried out to determine whether these pulps can be used as such for the production of writing and printing papers or whether they must be mixed with long-fibred pulps such as those from bamboos and sabai grass. Since in India the castor oil plant is grown for its seeds and oil production, it is considered that the stalks should be available at a cheap rate.

* Indiar Forest Leaflet No. 124: Indigenous Cellulosic Raw Materials for the Production of Pulp, Paper and Board. Part 2 Pulps for Writing and Printing Papers from the Castor Oil Plant Ricinus communis. By Dr. R. V. Bhat and Narendra S. Jaspal. Pp. ii +15 . (Delhi: Manager of Publications, 1951.) Annas 8; $9 \dot{d}$.

\section{ORNITHOLOGY IN THE U.S.S.R.}

$\mathrm{T}$

HE ornithology of the U.S.S.R. has been somewhat imperfectly known in other countries, especially of recent years. On behalf of the British Ornithologists' Union, Dr. Hans Johansen, formerly professor in the University of Tomsk and now of the Zoological Museum, Copenhagen, has prepared a paper which attempts to review the place of ornithological studies in the U.S.S.R. to-day (Ibis, 94, No. 1). Johansen's task has not been easy because no journal devoted entirely to ornithology has been published in the U.S.S.R.; some of the publications containing ornithological articles are unobtainable. Information about articles on ornithology can frequently only be obtained through lists of Russian literature, so that the articles cannot be seen or judged on merit. Although Johansen's survey must, therefore, necessarily be regarded as incomplete, the author is to be commended for undertaking a task which has involved consideration of not less than five hundred publications.

A summary of Johansen's article indicates that the old traditions of Russian ornithology were best and most strongly represented by faunistic reviews which have almost completely surveyed the whole of the enormous country. Large amounts of material were collected in the form of bird-skins, which made possible the systematic revision of many groups of birds. This again made possible broad concepts of the avifauna of the U.S.S.R. as a whole and the numerous zoogeographical and historical faunistic descriptions.

In addition to these old branches of work, new problems have arisen in recent times, as in the rest of the world. Of these, biological and ecological subjects are prominent and, among other things, have led to the production of ecological-geographical monographs on the birds of Russia.

Many investigations have also been made into the problems of bird migration; in addition to ringing and field observations, laboratory experiments have been made, with good results.

Some work has been done on anatomy and physiology in which attempts were made to connect them with biology, ecology and systematics. Investigations on parasites as well as the disadvantages and benefits of birds to forestry and agriculture were specially supported by the authorities.

If the accomplishments of the Russian ornithologists are considered from a wider and more international point of view it can be said that, on the whole, development has proceeded on the same lines as in other countries, though studies naturally show the peculiar influence of the country.

Because of the great extent of the country, from the Baltic to the Pacific Ocean and from high polar latitude to the subtropical conditions in the Transcaucasus, Russian ornithologists have done little work outside their own country. There is, however, the work of Zarudny in Persia and the numerous Russian expeditions made long ago in Mongolia and central Asia. In recent times these works were continued by Sushkin, Tugarinov, Sudilovskaia (Kashgaria) and, more especially, by Madame Kozlova.

The extent and variation of the U.S.S.R. have also been the reason why the so-called line of faunistic research has received special attention. In recent times, according to Russian information, the emphasis has shifted to ecological-geographical characteristics of entire taxonomic groups of birds. This can be regarded as a new branch of Russian ornithology, though publications have not been received in other countries.

Another speciality of Russian ornithology, which was started by Nikolai Severtzov so long ago as 1877 , is the profound zoogeographical analysis, which was chiefly combined with historical conclusions. Of the latest achievements, Stegmann's work on the ornithogeographical division of the Palæarctic Region can claim originality, since he provides new methods and techniques of zoogeographical description. 